\title{
Capital social, Internet e TV: controvérsias'
}

\section{Heloiza Matos}

- Pós-doutora pela Université Stendhal, França, em 1995 (Comunicação Política) e 2007 (Comunicação, Capital Social e Tecnologia)

- Doutora e Mestre em Ciências da Comunicação pela Universidade de São Paulo (USP)

- Jornalista pela Universidade Federal de Juiz de Fora (UFJF)

- Professora do Programa de Mestrado da Faculdade Cásper Líbero

- Professora da Escola de Comunicações e Artes (ECA) da USP até 2002

- Presidente do Instituto Ciência-Tecnologia da Comunicação

- Sócia da Media Training Ltda.

-heloizamatos@gmail.com

1 Pesquisa desenvolvida junto ao Gresec/ICM da Université Stendhal (Grenoble, França) e financiada pela Capes. 0 estudo tem continuidade em grupo de pesquisa do Mestrado da Faculdade Cásper Líbero. Partes deste artigo foram apresentadas no Compolítica, em 2007. 
O artigo analisa a evolução do conceito de capital social com base na formulação de Bourdieu, e seus desdobramentos entre os autores na Europa, Estados Unidos e Brasil. O conceito aparece como atributo individual e componente da ação coletiva nas redes sociais, influindo nos níveis de confiança e engajamento cívico. O texto enfatiza as formulações mais recentes da obra de Putnam, e da controvérsia provocada por sua posição, para quem a TV e a Internet estão diretamente implicadas no declínio do capital social.

PALAVRAS-CHAVE: CAPITAL SOCIAL・MÍDIA • TECNOLOGIAS • ENGAJAMENTO CÍVICO

\section{Abstract}

The article provides an analysis of the evolution of the social capital concept, based on Bourdieu's theory and its developments among European, North American and Brazilian authors. The concept appears as an individual attribute and part of the collective action within social networks, influencing at the trust and civic engagement levels. The text stresses the most recent theories of Putnam's work, and the controversy caused by his theories, to whom TV and the Internet are directly involved in the decline of social capital.

KEYWORDS: SOCIAL CAPITAL • MEDIAS • TECHNOLOGY • CIVIC ENGAGEMENT

\section{Resumen}

Se analiza la evolución del concepto de capital social, con base en la formulación de Bourdieu, y sus desdoblamientos entre los autores de Europa, Estados Unidos y Brasil. El concepto aparece como un atributo individual, que compone de la acción colectiva en las redes sociales e influye en los niveles de confianza y compromiso cívico. Se enfatizan las formulaciones más recientes de la obra de Putnam y la controversia provocada por su posición; para este autor, la televisión e Internet están directamente implicadas en la decadencia del capital social.

PALABRAS CLAVE: CAPITAL SOCIAL • MEDIOS DE COMUNICACIÓN SOCIAL • TECNOLOGía • COMPROMISO CÍVICO 
0 uando a TV surgiu na América nos anos 50, havia uma expectativa de que a nova mídia iria propiciar o crescimento do engajamento cívico e da consciência política dos cidadãos. Pela primeira vez na história, todos os cidadãos poderiam ter a mesma oportunidade de testemunhar fatos políticos importantes e de acompanhar os debates no parlamento (HOOGHE, 2002).

Depois de meio século, a tendência mudou: a disseminação da TV passou a ser vista como causa do declínio da vida pública e da coesão social. Putnam considera a TV como chave para entender a erosão gradual do capital social na sociedade americana. Atualmente, é a Internet que alimenta o debate acerca das possíveis relações entre as novas tecnologias de informação e comunicação (TICs) e o declínio do capital social.

\section{Capital social: perspectivas conceituais}

A primeira análise sistemática do conceito de capital social surgiu num artigo de Pierre Bourdieu, que o definiu como "o conjunto de recursos atuais e potenciais que estão ligados à posse de uma rede durável de relações mais ou menos institucionalizadas de conhecimento e reconhecimento mútuo" (BOURDIEU, 1980, p. 2), ou seja, o capital social seria um atributo do indivíduo num contexto social.

Outros autores tomam-no como componente da ação coletiva:

"Estar socialmente inserido no grupo significa, para o indivíduo, a busca de proveitos materiais e simbólicos e, entre os membros, implica na transformação das relações contingentes (vizinhança, trabalho, parentesco), necessárias e escolhidas, implicando obrigações duráveis subjetivamente acompanhadas de sentimentos de reconhecimento, respeito, amizade, ou garantidas institucionalmente." (PONTIEUX, 2006, p. 46)

Portes identifica o capital humano com o conhecimento e as habilidades adquiridas pelo indivíduo, enquanto o capital social se relacionaria com a dimensão e a qualidade das relações sociais. "Para possuir capital social, um indivíduo precisa se relacionar com outros, e são estes - não o próprio - a verdadeira fonte dos seus benefícios" (PORTES, 2000, p. 139). Na prática, o volume de capital social seria identificado com o nível de envolvimento associativo, ou seja, que o indivíduo pertença a uma comunidade civicamente engajada, participando em variadas redes de interação.

Outra característica apontada por Granjon e Lellong (2006) é que o capital social pode designar um conjunto de sociabilidades ou configurações relacionais específicas. Seria, ao mesmo tempo, um recurso e um instrumento de poder que se aplica tanto ao indivíduo como a uma coletividade (família, vizinhança, grupos de afinidades, etnias, localidades, região, nação). O capital social seria o resultado de uma escolha racional ou o efeito natural da vida social, podendo ser de ordem pública ou privada.

Para Norris (1996), citando Putnam, o capital social pode ser entendido como as densas redes de normas e de confiança social que capacitam os participantes a cooperar na busca de objetivos compartilhados. Segundo a autora, Putnam argumenta que 
quanto mais nos conectamos com outras pessoas, em uma interação face a face com a comunidade, mais confiamos nelas.

Bévort e Lallement (2006) apontam a publicação do artigo Making democracy, de Putnam, em 1995, como o ponto decisivo para o desenvolvimento de numerosos estudos correlacionando o índice de capital social com os níveis educacionais, nutricionais, de saúde e de emprego.

\section{Capital social no Brasil}

No Brasil, o capital social assume importância no final da década de 90. Uma publicação de resenha bibliográfica sobre o tema (ABU-EL-HAJ, 1999) indicava, à época, como únicas referências em português o livro de Putnam, Comunidade e democracia, publicado pela FGV em 1998, e uma obra de Fukuyama sobre os níveis de confiança como característica cultural essencial para o florescimento do capital social, de 1998.

A coletânea de textos organizada por Grau (1998) inclui um artigo de Charles Reily, em que o capital social é colocado como condição para o exercício da cidadania. E, ainda, numa obra sobre as desigualdades da América Latina, e, na seqüência, sobre a relação entre cultura e capital social, Bernardo Klisberg (2000) analisa o impacto do conceito e seu uso na região.

Especificamente sobre capital social, Baquero é um dos autores brasileiros que mais tem se dedicado a essa linha de pesquisa. Em 2004, organizou uma coletânea voltada para o estudo do capital social relacionado com a democracia e a juventude no Brasil. Em 2006, Baquero e Cremonese publicaram uma outra coletânea sobre a teoria e a prática do capital social. Nesta obra, na parte do livro sobre a dimensão conceitual, autores de vários campos do conhecimento fizeram um balanço crítico do conceito, analisando as especificidades e limites da aplicação do capital social no contexto brasileiro.

Em 2007, Aguiar publica uma obra direcionada para as desigualdades sociais, redes de sociabilidade e a participação política, como resultado de uma pesquisa realizada na área metropolitana de Belo Horizonte.

Em outras publicações, relacionadas com os conceitos de comunidade, cidadania e movimentos sociais, o capital social é relacionado com as redes sociais, mas sem um aprofundamento maior (ver KUNSCH e KUNSCH, 2007; PAIVA, 2003). A primeira obra, um texto de Peruzzo (2007) citando Franco, ressalta que, para o desenvolvimento econômico e social, é necessário que haja a passagem do capital humano para o capital social. E Franco reconhece que o caminho para essa passagem é oferecer condições para que os "beneficiários passivos" dos programas assistenciais sejam capazes, eles mesmos, de superar seus problemas e melhorar a qualidade das suas vidas. O autor define o capital social como a "capacidade de cooperar, formar redes, regular seus conflitos democraticamente e, enfim, constituir comunidade" (FRANCO, apud PERUZZO, 2007). 
Em Tocqueville não via TV, de 2006, Gomes discutiu a obra de Putnam, com especial atenção para a relação entre capital social, TV e democracia. O autor nega a relação entre a audiência de TV e a influência no nível do capital social. Contudo, talvez por escapar dos seus objetivos naquele artigo específico, o autor não se refere ao vínculo entre Internet, capital social e engajamento cívico. Outros autores brasileiros (RECUERO, 2007; LEMOS, 2003) também se interessaram pelo tema, sem necessariamente discutirem os três fatores que nos interessam diretamente: TICs, capital social e participação política.

Do ponto de vista do mercado e do terceiro setor, observam-se duas tendências: no campo da tecnologia da informação, o conceito do capital social tem sido tratado como sinônimo de internet social, ou seja, a Web 2.0 (VASQUES, 2008). Por outro lado, há uma tentativa de ampliação ou deslocamento do conceito de responsabilidade social, na direção do de capital social. A Comunitas, originária da Comunidade Solidária, cita como um dos seus objetivos o capital social (www.comunitas.org.br).

\section{Capital social em Robert Putnam}

O trabalho inicial de Putnam sobre o capital social foi publicado em 1995, resultado de uma longa pesquisa realizada em províncias italianas, numa tentativa de estabelecer relação entre as formas de organização social e a formação do capital social. No entanto, a obra que tornou Putnam conhecido, discutido e criticado foi Bowling alone, publicada em 2000.

Nesta obra, Putnam aborda o declínio da vida associativa e correlaciona este fato a uma queda da participação cívica por uma série de indicadores. Putnam afirma que a geração de indivíduos gregários está desaparecendo, e estaria sendo substituída pela geração de baby boomers que não têm o mesmo instinto. Em resumo, ele observa um declínio nos níveis de capital social.

Para o autor, algumas possíveis explicações para esse fenômeno de perda seriam: a liberação profissional progressiva das mulheres; a mobilidade física do local de trabalho e de moradia; mudanças demográficas com repercussões na família americana; a migração dos contatos da esfera real para a esfera midiática e, mais tarde, virtual.

Norris e Davis (2003, p. 410) observam que, para Putnam, muitas sociedades pósindustriais têm enfrentado "(i) um declínio geral na filiação massiva em instituições vinculativas tradicionais; e também (ii) o aumento simultâneo de formas de conexão social mais informais, fluidas e pessoais, que possuem orientação mais individualista."

Em relação à televisão, Putnam (2002, p. 295), ao comparar as gerações dos anos 1930 com a dos anos 1960, diz que o que estaria diminuindo não é somente a leitura de jornais, mas o interesse pelas notícias em si. O número de pessoas que vêem a notícia pela TV ou que buscam a informação na mídia impressa estaria em declínio. 
Putnam também reivindica que a televisão destruiu o capital social de maneira mais óbvia, substituindo as atividades sociais e de lazer fora de casa. Mas ele também sugere que a televisão pode ter produzido uma visão mais cínica do mundo entre os telespectadores.

Ver mais TV significaria reduzir qualquer forma de participação cívica e de implicação social: "cada hora adicional de TV significa uma redução de $10 \%$ aproximadamente na maioria das formas de ativismo cívico: menos reuniões públicas, menos membros para comitês locais, menos cartas enviadas ao congresso, etc." (PUTNAM, 2002, p. 306). O consumo de TV na América reduziria, também, algumas atividades individuais entre $10 \%$ e $15 \%$, tais como comunicações escritas, orais e eletrônicas.

Embora aponte a necessidade de considerar outras variáveis (idade, pobreza, escolaridade), e de afirmar que "a correlação não demonstra a existência de causa", para Putnam nada "está associado de forma tão ampla com o abandono do compromisso cívico e com a desvinculação social como a dependência da TV para o entretenimento" (PUTNAM, 2002, p. 310).

Por outro lado, pesquisas constataram que ver TV cultivaria a insegurança e levaria ao sentimento de desconfiança, sendo a TV acusada, pelo formato e pelo conteúdo de sua programação, de reforçar atitudes cínicas em relação à política e à sociedade (HOOGHE, 2002).

Em relação à Internet, Putnam (2002, p. 297) considera os americanos tecnologicamente avançados como socialmente mais isolados, tendendo a estarem menos comprometidos civicamente quando comparados com outros que buscam informação na imprensa, rádio e TV. No entanto, afirma: "Isto não prova que a rede seja socialmente desmotivadora”.

Putnam lembra igualmente que quando a Internet alcançou $10 \%$ dos americanos, em 1996, o declínio da vinculação social e do engajamento cívico na América já tinha, pelo menos, 25 anos de existência. Assim, não se poderia afirmar que as relações sociais simplesmente se deslocaram do espaço físico para o virtual. Para ele, "a Internet poderia fazer parte da solução do problema cívico ou ainda exacerbá-lo, mas a revolução cibernética não o provocou" (PUTNAM, p. 227). Mais adiante, afirma que é cedo para avaliar os efeitos sociais da Internet a longo prazo.

Afinal, quais seriam os efeitos (se os há) das TICs sobre os vínculos sociais e o engajamento cívico? Tanto a história do telefone, da televisão, e os primeiros dados sobre o uso da Internet constituem um indício de que a comunicação mediada pelo computador acabará complementando (e não substituindo) as comunidades face a face. Mas, acerca do capital social virtual, Putnam arremata: "É muito pouco o que se pode dizer, com segurança, sobre a vinculação entre capital social e a tecnologia da Internet" (2002, p. 226). 


\section{Críticas ao capital social e a Putnam}

No entanto, a sociabilidade nem sempre traz somente resultados positivos. O capital social pode ter, assim, um lado escuro. Alguns autores estudaram os grupos do narcotráfico na América Latina, as famílias da máfia, os círculos de jogo e de prostituição e as gangues juvenis para ilustrar como o encastelamento em certas estruturas relacionais pode redundar em resultados socialmente indesejáveis (por ex. PORTES, p. 146-149).

A sociabilidade pode ter efeitos contraditórios: ser fonte de bens públicos, e também levar a males públicos. Estudos recentes identificaram pelo menos quatro conseqüências negativas do capital social: exclusão dos não membros, exigências excessivas a membros do grupo, restrições à liberdade individual e normas de nivelação descendente.

Uslaner (2000) considera que o círculo vicioso entre o engajamento cívico, a confiança e a socialização é uma questão mal colocada por Putnam. Para ele, não faria sentido confiar gratuita e facilmente em estranhos. A confiança seria, ao contrário, um resultado do compartilhamento progressivo e apreendido de valores.

Por sua vez, Skocpol afirma que Putnam aplica uma mesma ferramenta (o capital social) como panacéia para entender todos os problemas (cívicos, políticos, comunicacionais). Diz, inclusive, não usar o termo capital social, por discordar da teoria que considera "que as associações ao nível local engendram a confiança que é o lubrificante e o mecanismo que permitem a democracia e o funcionamento do governo" (VAN ROY, 2001). Do ponto de vista histórico, Skocpol vê a tese de Putnam como superficial e ingênua por conter erros sobre o desenvolvimento do voluntariado na América.

Para esta autora, não seria suficiente, para explicar o declínio da vida associativa americana, aceitar que atualmente os cidadãos americanos desertam das associações porque eles ficam em casa em frente ao televisor. O problema seria de ordem institucional: faltaria liderança adequada para defender as organizações modeladas pela política.

Já Ficher (2001, p. 17-22), citado por Welmann et alii (2001), vê dois problemas com as interpretações de Putnam. Primeiro, o decréscimo no capital social não seria constante ao longo de todas as suas medidas. Ainda que a maioria dos indicadores de envolvimento político mostrasse um declínio constante, os indicadores de socialização e de visitas (aos amigos, parentes e vizinhos) seriam inconsistentes. Para este autor, essa inconsistência das medidas questionaria a validade e a confiabilidade da tese de Putnam. O segundo problema estaria relacionado a como interpretar o quantum de decréscimo observado. O decréscimo que Putnam vê como substancial, Ficher o compreende como negligenciável e de curto prazo.

Shudson (1996, p. 19) sugere que o trabalho de Putnam desconsiderou algumas evidências-chave em sua análise do declínio cívico. Em suas palavras:

"Se nós pudéssemos medir a participação civica melhor, o declínio seria menos impactante e o mosaico menos perplexificante. Se nós olharmos mais cuidadosamente para 
a história da participação cívica e para as diferenças entre gerações, nós deveríamos abandonar a retórica do declínio. E se nós examinássemos a história recente da televisão mais de perto, nós não poderíamos culpar a TV pelo 'desligamento' do envolvimento cívico."

E arremata: "As medidas de Putnam devem ter olhado superficialmente vários tipos de atividade cívica."

Mas mesmo se, para Putnam, o tempo passado diante da TV diminui ou impede as atividades cívicas e a participação política, a evidência empírica sobre a TV não seria assim tão clara (HOOGHE, 2002). A maior parte dos estudos não apontaria efeitos significativos e fortes.

Estudo em uma comunidade neerlandesa (HOOGHE, 2002) mostra que a TV pode ter mesmo um efeito positivo, ou seja, que ver TV estaria associado positivamente (e não negativamente, como quer Putnam) com o interesse sobre o sistema político. Assim, expor-se a informações políticas na TV poderia aumentar (e não diminuir) o conhecimento sobre assuntos políticos e o engajamento cívico.

Por outro lado, nesses casos, o tipo do programa e a natureza do canal fariam diferença: programas de entretenimento teriam efeitos negativos, enquanto programas de noticiário gerariam um resultado positivo; um canal público poderia estimular as atitudes cívicas, enquanto os canais comerciais emulariam valores menos cívicos na audiência.

Por fim, Woolcock (2001), ao indicar as críticas que estavam sendo feitas ao capital social, aponta que o conceito de capital social se serve de velhas idéias sob nova roupagem, carecendo de substância enquanto figura apenas como "a última moda das ciências sociais".

\section{Participação política, TICs e capital social}

Os cientistas políticos introduziram uma virada conceptual ao fazerem equivaler o capital social ao nível de civismo em comunidades (PORTES). Esta virtude cívica estaria presente nas cidades em que os habitantes votam, obedecem à lei e cooperam entre si, e cujos dirigentes são honestos e empenhados no bem comum (PUTNAM, 1995). No limite, a virtude cívica seria o fator que diferenciaria as comunidades bem governadas das mal governadas.

O reverso da moeda seria o vício cívico: cidadãos desconectados, que não se reúnem, que não sociabilizam, que não confiam uns nos outros, que não discutem nem votam, que não respeitam a lei e que valorizam a esfera particular acima do interesse público. Para Putnam, os principais vilões dessa corrosão do caráter cidadão (do declínio do capital social) seriam a TV e a Internet (USLANER, 2000). 
Cabe então analisar mais detalhadamente o impacto das tecnologias da informação e da comunicação (TICs) sobre a participação política nas comunidades, buscando compreender as interfaces entre TV e Internet, mais especificamente, por referência aos níveis de capital social.

Televisão e capital social

Norris (1996) considera que a notícia televisiva está fortemente associada com o engajamento político. Hooghe (2002) defende que ver TV em estações comerciais está positivamente associado com o enfraquecimento da mentalidade política. Já a relação com o noticiário seria inversa, isto é, estaria negativamente associada: logo, fortaleceria a mentalidade política.

Tanto para Norris (1996) quanto para Hooghe (2002), não há evidência de uma relação negativa entre usar a mídia para buscar informações políticas e o interesse político; ao contrário, a relação tende a ser positiva. Entretanto, essa relação positiva não deve implicar que a TV pode levar a um forte engajamento cívico ou a um maior conhecimento sobre temas políticos. Nas palavras do autor, a "pesquisa demonstra, sim, que aqueles que assistem noticiários de TV são mais bem informados sobre política e, que então serão mais inclinados a participar da vida social e política" (HOOGHE, 2002, p. 15).

Hooghe cita pesquisas de Milner que tentam correlacionar a exposição midiática de jovens de 14 anos com uma futura propensão a votar, ou seja, com uma futura tendência por participação político-eleitoral.

Gerbner et alii (1980, p. 16), citado por Hooghe, argumentam que, pelo fato de os telespectadores estarem mergulhados em informações e imagens de violência e crime, eles se sentiriam mais ameaçados na vida cotidiana e, consequentemente, esse sentimento poderia erodir seu desejo de participar em ações coletivas - incluindo ações políticas. Poderia estar em jogo um mecanismo de isolamento: muito tempo gasto com TV alienaria da vida social, e esse descompasso da observação real seria compensado por especulações sobre a vida na comunidade. A relação oposta também se sustentaria: porque as pessoas estão com medo da criminalidade na vizinhança, elas preferem ficar em casa vendo TV.

De toda forma, Hooghe (2002:19) conclui que, ao "oferecer divertimento leve e fórmulas simples, as estações comerciais contribuem ao cultivo de uma cultura do cinismo político, da insegurança e do isolamento".

De modo particular, os valores jornalísticos tenderiam a assumir um viés antipolítico, cético com relação às principais instituições da sociedade. A imprensa supervalorizaria a mudança, ao invés da continuidade, tecendo críticas inesgotáveis àqueles posicionados na administração política, valorizando questões de caráter pessoal em detrimento do debate político. Os partidos tenderiam a ser tratados sob uma luz ex- 
tremamente negativa. Junto ao público, isso produziria uma visão excessivamente cínica, mal- informada e negativa dos políticos, o que levaria a um distanciamento entre candidatos e eleitores, e aumentaria a desconfiança com relação ao processo eleitoral (HOOGHE, 2002).

Contudo, estudos demonstram que cidadãos confiantes não são aqueles que supostamente mais votam, que se engajam em atividades de campanha, ou que estão interessados em política (CITRIN, 1974; ROSENSTONE e HANSEN, 1993, apud NORRIS, 1996). Teoricamente, esses fatores podem não estar relacionados. Assim, neste caso, as mídias poderiam produzir um público mais cético sem acarretar conseqüências significantes para o ativismo político.

Internet e capital social

Para os Estados Unidos e Europa, Norris (2003) observou que a Internet não mobilizou grupos que eram anteriormente inativos (com exceção parcial dos jovens), mas, pelo contrário, fez reforçar as tendências pré-existentes em participação política.

Wellman e Hogan (2006, p. 46) argumentam que a Internet contribuiria para todas as formas de contato: interpessoal, intra e interorganizacional. Longe de distanciar as pessoas, a Internet favoreceria sua proximidade. E que o uso de uma mídia induziria ao uso de outras mídias: quanto mais as pessoas se comunicam pelo menos por uma mídia qualquer, mais elas se comunicam pela Internet. Assim, comunicações mediadas aumentariam a rede de relacionamentos.

Para eles, o individualismo na Internet teria efeitos profundos sobre a coesão social. Mais do que fazer parte de uma hierarquia de grupos cada vez mais integrados, o indivíduo agora faz parte de comunidades múltiplas e parciais (WELLMAN E HOGAN, p. 52). Apesar das redes sociais menos densas, os laços sociais parecem ter aumentado. Isso resultaria em contatos interpessoais mais numerosos e freqüentes do que antes. No meio desta mudança em direção ao individualismo da rede, é a natureza mesma da cidadania que muda.

Essa transformação teria começado antes da Internet, mas é a presença dela que aceleraria e remodelaria o processo. De qualquer forma, os efeitos da Internet não seriam nem tecnologicamente determinados nem sociologicamente predestinados.

Stromer-Galley (apud HOWARD e JONES, 2004, p. 6) encontrou indícios da relação entre a familiaridade com o uso da Internet e a propensão por votar on-line: de um lado, quando mais gente usa a Internet, maior o número de pessoas dispostas a votar on-line; de outro lado, a familiaridade com a tecnologia parece ter pouca relação com o sentido de dever e interesse político das pessoas. Logo, o uso da mídia e a motivação para participar politicamente parecem estar desconectados; assim, a tecnologia parece mais predispor as pessoas a aceitarem um processo on-line de votação do que propriamente emular um sentido de dever de participar votando. 
Rice e Katz (apud HOWARD e JONES, 2004, p. 6) mostram como as pessoas têm usado a Internet para enriquecer suas vidas políticas - participando de grupos de discussão on-line, pesquisando sobre candidatos e opções de política, e mesmo acompanhando o noticiário político.

Para Wellman et alii. (2001), a Internet transformaria o capital social quando, em razão de sua ampla difusão, ela restabelecesse um senso de comunidade ao conectar amigos, provesse fontes de informação em uma variedade ampla de assuntos e engajasse vários grupos em participação política e organizacional; a Internet diminuiria o capital social se, por suas capacidades de informar e entreter, ela afastasse as pessoas da família e dos amigos (contribuindo, assim, para reduzir o interesse na comunidade local e em sua política); e a Internet suplementaria o capital social quando ela se adicionasse à configuração existente de comunicação e mídia, para facilitar as relações sociais correntes e os padrões seguidos de engajamento cívico e socialização.

Por fim, a Internet tem levado a novas formas de comunicação com os usuários utilizando geralmente as ferramentas de comunicação de formas inéditas. Por exemplo, o uso de SMS nos celulares aumenta o contato social porque é geralmente usado para marcar encontros face a face com amigos próximos.

\section{Conclusões}

A análise apresentada sugere que a relação entre o engajamento cívico e o consumo da televisão é mais complexa do que algumas vezes sugerido. Enquanto a quantidade de tela parece corroborar a tese de Putnam, outras evidências concernentes ao que os telespectadores americanos assistem sugerem que noticiários, e particularmente programas dedicados a explorar questões atuais, não parece ser danoso à saúde democrática da sociedade, e pode mesmo provar-se benéfico. Em suma, a acusação de que a televisão é a fonte causadora da falta de confiança e crença na democracia americana parece, sob essa base (na versão fraca), carecer de provas, e pode até (na reivindicação forte) parecer profundamente implausível (HOOGHE, p. 7-8).

Para Portes, o investigador do capital social teria que cumprir algumas precauções em sua pesquisa: em primeiro lugar, deveria separar a definição do conceito, teórica e empiricamente, dos seus alegados efeitos; em segundo lugar, deveria estabelecer controles do sentido da relação, de forma a demonstrar que a presença do capital social é anterior aos resultados que se espera que produza; em terceiro lugar, deveria controlar a presença de outros fatores que podem explicar tanto o capital social como os seus alegados efeitos; e, em quarto lugar, deveria identificar as origens históricas do capital social da comunidade de um modo sistemático.

Depois de tudo o que foi dito, não há substrato para afirmar que a Internet é boa ou má. Mas certamente a Internet não é um reservatório de capital social. Não há 
evidência de que a Internet esteja afastando as pessoas dos laços sociais tradicionais ou tornando-as menos confiantes. Em si mesma, a Internet não é nem ameaça nem panacéia para a sociedade civil e a sociabilidade (USLANER, 2000).

\section{Referências}

ABU-EL-HAJ, J. 0 debate em torno do capital social: uma revisão crítica. Revista Brasileira de Informação Bibliográfica em Ciências Sociais - BIB, n. 47, p. 65-79, 1 sem., Rio de Janeiro, 1999.

AGUIAR, Neuma (org). Desigualdades sociais, redes de sociabilidade e participação política. Belo Horizonte: Editora UFMG, 2007.

BAQUERO, Marcello (org). Democracia, juventude e capital social no Brasil. Porto Alegre: Editora UFRGS, 2004.

BAQUERO, Marcello; CREMONESE, Dejalma (orgs.). Capital social - teoria e prática. ljuí: Editora Unijuí, 2006.

BÉVORT, A.; LALLEMENT, M. Introduction. Le capital social: territoires et tribulations. In: BEVORT, A.; LALLEMENT, M. (dirs). Le capital social. performance, équité et réciprocité. Paris: Éditions La Découverte/MAUSS, 2006.

BOURDIEU, Pierre. Le capital social. notes provisoires. In: Actes de la Recherche in Sciences Sociales, 31, n. 31, 2-3, 1980.

FUKUYAMA, F. Confiança: as virtudes sociais e a criação da prosperidade. Rio de Janeiro: Rocco, 1998.

GOMES, Wilson. Tocqueville não via TV: capital social, democracia e televisão em Robert Putnam. In: GT de Comunicação e Política, XV Encontro da Compós, Unesp, Bauru, 2006.

GRANJON, Fabien; LELONG, Benoit. Capital social, stratifications et technologies de l'information et de la communication. In: Revue Réseaux, n 139, UMLV/Lavoisier, pp. 149-173, 2006.

GRAU, Núria Conill. Repensando o público através da sociedade: novas formas de gestão pública e representação social. Brasília: Enap, 1998.

HAMPTON, K. N.; WELMANN, B. Netville on-line and off-line. In: American Behavior Scientist, v. 43, n. 3, nov., Sage Publications Inc., 1999.

HOWARD, Philip; JONES, Steven. Embedded media: who we know, what we know, and society online. In: Society Online: The Internet in Context, Thousand Oaks, CA: Sage, 2004.

HOOGHE, Marc. Television and civic attitudes - the effect of television time, programmes and stations. In: Ethical Perspectives, Volume 9, issue 4, December, 2002.

KLISBERG, Bernardo. Desigualdade na América Latina: o debate adiado. São Paulo: Cortez/Unesco, 2000.

KUNSCH, Margarida M. K.; KUNSCH, Waldemar L. (orgs). Relações públicas comunitárias - a comunicação em uma perspectiva dialógica e transformadora. São Paulo: Summus Editorial, 2007.

LEMOS, André. Cibercidades. Um modelo de inteligência coletiva. In: XXVI Intercom, Núcleo de TICs, Belo Horizonte, setembro, 2003.

MATOS, Heloiza. Comunicação política e comunicação pública. In: Revista Organicom, n. 4, ECA/USP, São Paulo, 2006. Comunicação pública, esfera pública e capital social. In: DUARTE, Jorge. Comunicação pública, estado, mercado e interesse público. São Paulo: Atlas, 2007. pp. 47-58. Comunicação pública e capital social: dimensões e interfaces. PUC-MG/Annablume, 2008.

NORRIS, Pippa; DAVIS, James. A transatlantic divide? Social capital in the United States and Europe. In: European Social Survey Launch Conference, Brussels, 25-26 November, 2003. Did television erode social capital? A reply to Putnam. In: PS: Political Science and Politics. XXIX (3) September, p. 474-480, 1996.

PAIVA, Raquel. 0 espírito comum - comunidade, mídia e globalismo. Rio de Janeiro: Mauad, 2003.

PERUZZO, Cicilia M. K. Cidadania, comunicação e desenvolvimento social. In: KUNSCH, M. M. K.; KUNSCH, W. L. (orgs). Relações públicas comunitárias - a comunicação em uma perspectiva dialógica e transformadora. São Paulo: Summus Editorial, 2007.

PONTHIEUX, Sophie. Le capital social. Paris : La Découverte, 2006.

PORTES, Alejandro. Capital social: origens e aplicações na sociologia contemporânea. Revista Sociologia, Problemas e Práticas, $\mathrm{n}^{\circ} 33$, pp. 133-158, 2000.

PUTNAM, Robert et alii. Making democracy work. Princeton: Princeton University Press, 1995. Bowling alone: America's declining social capital. In: Journal of Democracy, Janeiro, v. 6, n. 1, pp. 65-78, 1995. Bowling alone: the colapse and a revival of American community. Simon \& Schuster, New York, 2000. Solo en la bolera. Colapso y surgimiento de la comunidad norte-americana. Barcelona: Galaxia Gutemberg, 2002. 
Measure and conséquences du social capital. Isuma, Vol. 2, № 1, Spring 2001, pp. 47-58, 2001.

RECUERO, Raquel da Cunha. 0 estudo do capital social gerado a partir das redes sociais no Orkut e nos weblogs. Curitiba: Compós, 2007.

SKOCPOL, Theda. Unravelling from above. The American Prospect, no. 25, March-April, 1996.

. The Tocqueville problem. Civic engagement in American democracy. Social Science History, 21:4, Pittsburgh, winter, 1997.

SCHUDSON, Michael. What if civic life didn't die? The American Prospect. março/abril, pp. 17-20, 1996.

USLANER, Eric M. The civic engagement and the internet. Workshop on Electronic Democracy: Mobilization, Organization and Participation via New ICTs. University of Grenoble, 2000.

VAN ROOY, Alison. Comptes rendus. Isuma, Vol 2, n. 1, pp. 149-153, 2001.

VASQUES, Eduardo. Bem-vindo à internet social. B2B Magazine, Ano 7, n. 86, maio de 2008.

WELLMAN, Barry; HOGAN, Bernie. L'Internet, une présence immanente. In : PROULX, Serge et alii. Communautés Virtuelles: Penser et Agir en Réseau. Canada : Presse de l'Université Laval, 2006.

WELLMANN, B., QUAN-HAASE.; WHITE J.; and HAMPTON, K. Does the internet increase, decrease or supplement social capital? Social Networks, Participation and Community Commitment. American Behavior Scientist, 45 (3), 2001.

WOOLCOCK, Michael. La importancia del capital social para comprender los resultados económicos y sociales, 2001. Acesso em: 10/2007. Disponível em: <http://www.preval.org/documentos/00489.pdf> 